\title{
Evaluating tobacco industry 'transformation': a proposed rubric and analysis
}

\author{
Richard Edwards ๑, ' Janet Hoek $\odot,{ }^{1}$ Nancy Karreman, ${ }^{2}$ Anna Gilmore ${ }^{3}$
}

- Additional supplemental material is published online only. To view, please visit the journal online (http://dx.doi. org/10.1136/tobaccocontrol2021-056687).

${ }^{1}$ Department of Public Health, University of Otago, Wellington, New Zealand

${ }^{2}$ MRC Epidemiology Unit, Cambridge University School of Clinical Medicine, Cambridge, UK

${ }^{3}$ Tobacco Control Research Group, University of Bath, Bath, UK

\section{Correspondence to} Prof Richard Edwards, Department of Public Health, University of Otago, Newtown, Wellington, 6021, New Zealand; richard.edwards@otago.ac.nz

Received 31 March 2021 Accepted 12 November 2021

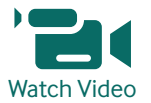

tobaccocontrol.bmj.com

(C) Author(s) (or their employer(s)) 2022. No commercial re-use. See rights and permissions. Published by BMJ.

To cite: Edwards R, Hoek J,

Karreman $\mathrm{N}$, et al.

Tob Control

2022:31:313-321

\section{ABSTRACT}

Some tobacco companies claim they are 'transforming' by adopting harm reduction goals or even seeking to achieve a 'smokefree' world. What characterises transformation and whether companies can or are transforming is unclear. Nevertheless, such claims are gaining traction. We critically investigated tobacco industry transformation by exploring the definition and criteria for evaluating transformation, and assessed whether transformation is occurring and feasible. Companies' transformation claims centre on increasing sales of new tobacco and nicotine products like e-cigarettes ('new products') with little attention to reducing sales of more hazardous smoked and oral products ('conventional products').

We define a transforming tobacco company as one demonstrating substantial, rapid and verifiable progress towards eliminating the production and sale of conventional tobacco products within 5 years in all markets where it operates.

We found no evidence any tobacco company is meeting the three essential criteria of rapidly progressing towards eliminating conventional products, ceasing to obstruct effective tobacco control measures and taking action to minimise smoking uptake and disparities. While some companies are developing new product portfolios, their actions are more consistent with profit maximisation than eliminating conventional product use. This approach is best described as 'pseudo-transformation', designed to delay implementation of effective tobacco control policies. In addition, our analysis suggests replacing conventional products with new nicotine products is unlikely to be a viable long-term business model. Public health practitioners should not rely on tobacco industry claims but should lead the transformation debate, establish credible definitions and criteria, and monitor and assess whether transformation is occurring.

\section{INTRODUCTION}

Because its core product causes millions of avoidable premature deaths ${ }^{1}$ and it has consistently promoted its interests above population health, the tobacco industry is widely regarded as a pariah industry. However, recent claims by some companies that they are 'transforming' (box 1) raise important questions about what transforming should entail and how to evaluate industry claims. ${ }^{2-8}$

Although the public health community regards tobacco companies' interests as antithetical to public health and sees industry interference as a key barrier to effective tobacco control policies, ${ }^{9}$ the transformation narrative is gaining traction. Recent analyses concluded that some industry strategies 'start to look convincingly reasonable,${ }^{10}$ noted that the emergence of lower risk nicotine products is ' $a$ new opportunity to dramatically transform the cigarette business in ways that were never imagined ${ }^{, 11}$ and called on the WHO to support tobacco companies' transition to low-risk products. ${ }^{12}$

Great care must be taken to assess industry narratives and language such as 'transformation'. Corporations are adept at using deceptive framing and rhetoric to shape norms and beliefs, influence political and policy agendas and position themselves as part of the solution rather than being the problem. ${ }^{13-16}$ The leading proponent of transformation, Philip Morris International (PMI), funds the Foundation for a Smoke-Free World (FSFW) which recently embellished the transformation narrative by launching the 'Tobacco Transformation Index' (TTI). This 'index' purports to measure the degree to which leading tobacco companies are transforming. ${ }^{17} 18$

We critically investigated tobacco industry transformation by exploring the definition and criteria for evaluating transformation, assessing whether transformation is occurring and evaluating its feasibility.

\section{METHODS}

After identifying and critiquing transformation characteristics inferred from industry statements and the TTI, ${ }^{17} 1920$ we developed a definition and identified three essential and one secondary criteria that a truly transforming company must meet. Using documentary evidence, including the $\mathrm{TTI}^{17}$ and an analysis of Euromonitor data on tobacco sales, ${ }^{21}$ we assessed whether tobacco companies' actions meet these criteria, focusing particularly on PMI because of its wide-ranging transformation claims. We note the need for caution regarding the TTI, which has been criticised for its lack of independence and flawed methodology. ${ }^{17} 182223$

\section{RESULTS}

\section{Existing definitions and characteristics of transformation}

Analysis of industry documentation (box 1) indicates tobacco companies view transformation largely as increasing production of 'smoke-free', 'reduced risk', 'non-combustible' or 'next generation' products (henceforth 'new products'). ${ }^{25} 7$ Some companies have made non-specific statements about working towards a 'smoke-free' or 'noncombustible' future, contributing to harm reduction and reducing the harms their products cause, but none have committed to rapidly end the sales of smoked and oral tobacco products (henceforth 'conventional products'). 
Box 1 Tobacco industry claims of transformation.

Philip Morris International (PMI) announced their intent to transform in 2016 and have since variously claimed to be building a 'smokefree future', 'unsmoking' the world and helping smokers to 'unsmoke'. 826148

British American Tobacco (BAT) states its purpose is 'To build $A$ Better Tomorrow by reducing the health impact of our business ${ }^{\prime 5}$ and that people who smoke and cannot quit should be encouraged to switch to 'reduced risk alternatives'. ${ }^{3}$ They recently claimed that their transformation is 'accelerating'. Imperial Brands claims it is developing a sustainable 'Next Generation Product' business and making a 'meaningful contribution to harm reduction' as part of its 'environmental, social and governance' responsibilities. ${ }^{7}$

Altria claims it will 'transform Altria and our industry' and its 10 -year vision is to 'Responsibly lead the transition of adult smokers to a non-combustible future.'?

The TTI defines transformation as 'transformation of the global tobacco industry for the benefit of public health ${ }^{18}$ and the TTI report describes the index as a tool to quantify progress towards a 'world free of combustible cigarettes and other high-risk tobacco products'. ${ }^{17}$ However, the TTI's approach aligns with the tobacco industry's focus on transformation through increasing production of new products. For example, only one of the four activities the TTI assesses concerns phasing out conventional products; the others measure the development and marketing of new products. The TTI's product sales metrics apply a weighting of $90 \%$ for measures of the conventional:new products sales ratios and only $10 \%$ for measures of decline in conventional product sales. ${ }^{20}$ The TTI did not adopt stakeholders' suggestions to assess whether tobacco companies are impeding tobacco control measures. ${ }^{19}$

The self-interest evident in the industry's narrative suggests the public health community should develop its own definition, criteria and metrics for measuring transformation.

\section{Definition of a transforming tobacco company}

To transform means to markedly change in form, nature or appearance. Given the highly addictive and deadly nature of tobacco products, ${ }^{24}$ industry transformation must have at its core the rapid elimination of the production and sale of its conventional products. We propose that a transforming tobacco company must demonstrate substantial, rapid and verifiable progress towards eliminating the production and sale of conventional tobacco products within 5 years, and must do so in all markets in which it operates. This timeline recognises the urgency of ending the smoking epidemic and the need to allow companies time to transition.

In our review of evidence for transformation we have emphasised data on smoked tobacco product sales as these cause the greatest harms to population health. However, oral tobacco products should also be indicators where these contribute substantially to tobacco product use prevalence and tobaccorelated morbidity and mortality (eg, India, Myanmar and Sudan).

\section{Characteristics of a transforming tobacco company and review of evidence companies are transforming}

We propose four criteria to assess transformation. The first three are essential while the fourth is secondary. Meeting the fourth criterion does not provide evidence a company is transforming unless the first three criteria are also met. We describe each criterion and its rationale, and briefly assess progress towards meeting it. Further details of proposed metrics and evidence for transformation are presented in the online supplemental table.

Criterion 1: evidence of substantial progress towards eliminating the production, distribution, marketing and sales of conventional tobacco products within 5 years

A transforming company should demonstrate progress in eliminating conventional tobacco products in all markets where it operates, especially countries where sales are growing (eg, lower and middle-income countries (LMICs)). This requirement prevents companies from falsely claiming they are transforming based on actions in high-income countries (HICs), where sales are already declining (as a result of successful tobacco control measures), while maximising conventional product sales in LMICs, where growth remains possible. ${ }^{25}$

A transforming company should set a target for eliminating the production and sales of conventional products within 5 years, supported by an implementation plan. The plan should include difficult to reverse measures, such as closing production and distribution facilities, cancelling distribution contracts, relinquishing trademarks, withdrawing brands from sale and eliminating design features that contribute to the appeal, palatability and addictiveness of conventional tobacco products. The plan should also set out a reporting framework and should be subject to evaluation by independently appointed external monitors who have full access to internal information such as production, sales and marketing data; or product design and constituents.

\section{Evidence for transformation?}

There is no evidence that any company is meeting this criterion. Even the FSFW-funded TTI found that during 2017-2019 when the transformation narrative became established smoked tobacco sales among 15 leading companies declined by only $1.2 \%$ per annum globally. ${ }^{17}$ Our analysis of Euromonitor data indicates that PMI's smoked tobacco sales declined at a similar rate before (2012-2017) and after (2017-2019) adoption of their 'smokefree vision'. ${ }^{21}$

No tobacco company has committed to ending the production and sale of conventional tobacco products in all its markets within 5 years, or indeed within any time period. The TTI report provides no evidence of any company having a plan to eliminate conventional tobacco product sales; we have not found this evidence elsewhere. PMI has announced a goal to reduce combustible tobacco product sales, but its goal has no timeline and proposes only 'aspirational' annual reductions in shipments for 2019-2025. 27 Our analysis of Euromonitor data shows PMI's projected reductions are less than those observed from 2012 to $2019 .{ }^{21}$ If this aspirational rate of reduction was maintained, zero shipments would not occur until 2043, one year later than if the 2012-2019 rate of decline continued (see online supplemental table). ${ }^{26}$

While PMI has claimed it intends to stop selling combustible tobacco products in the UK, its undertaking has several caveats. First, it promises to cease sales in 10 , not 5 , years; second, the claim applies to a single HIC where smoking prevalence has declined rapidly; third, PMI has less than $10 \%$ market share in the UK, meaning it has little to lose by stopping sales there. ${ }^{28} 29$ Meanwhile, in LMICs PMI has continued to launch new conventional tobacco product lines with supporting marketing. ${ }^{6} 3031$

Industry-wide transformation should result in rapidly declining global sales of tobacco products, paralleled by 
accelerating decreases in consumption and smoking prevalence. There is no evidence that these changes are occurring. Global cigarette sales of cigarettes peaked in 2012 and have declined slowly since. The rate of decline has not accelerated and may even have slowed since 2017 (see online supplemental table). ${ }^{1721}$ Similarly, smoking prevalence in recent years declined slowly in most countries, ${ }^{21}$ with HICs showing greater decreases than LMICs. ${ }^{632}$ Estimates of global smoking prevalence trends find that the decline in prevalence slowed after $2015^{33}$ and forward projections suggest a gradual decline will continue to $2025 .^{132}$
Criterion 2: no obstruction of core and innovative tobacco control measures in any jurisdiction

Evidence-based population-based policy measures, such as those recommended in the Framework Convention for Tobacco Control (FCTC) (see table 1), are key drivers of declining global smoking prevalence. ${ }^{34-38}$ Implementing core FCTC (MPOWER: Monitor tobacco use and prevention policies; Protect people from tobacco smoke; Offer help to quit tobacco use; Warn about the dangers of tobacco; Enforce bans on tobacco advertising, promotion and sponsorship; Raise taxes on tobacco) measures to the highest level is essential to accelerate reductions in smoking

Table 1 Examples of tobacco control measures that a transforming or transformed company should not obstruct

\begin{tabular}{ll}
\hline Intervention domain & Tobacco control interventions transforming companies should \\
not oppose or obstruct
\end{tabular}

Supporting actions that transforming companies might take

Actions to prevent undermining of tax/price measures, including:

- Minimal price spread across brand portfolio.

- No use of differential price rises, price smoothing cushioning or proliferation of 'budget' brands.

- No use of price-related marketing strategies like discounting.

- Removal of tobacco products from duty-free sales outlets.

Actions to reduce company marketing of tobacco products and support enforcement of marketing restrictions, including:

- Elimination of all tobacco product marketing and marketing-related expenditure at local/national/crossnational level.

- Cease use of influencers and other social media marketing.

- Full compliance with independent regulators charged with monitoring and enforcing compliance with marketing restrictions.

- Verifiable steps to identify, report and eliminate any efforts by the company and its staff to subvert marketing restrictions.

Product supply and availability Measures to restrict the supply and availability of tobacco products, including:

Restricting store types where tobacco can be sold

- Tobacco retailer licensing, and proximity or density controls on tobacco retailers.

Increases in age-related sales restrictions (eg, Tobacco 21 laws).

- Progressive increases in age-related sales restrictions (tobaccofree generation).

- A gradual phasing out of the sale of conventional tobacco products.

Implementation of the Illicit Trade Protocol and government interventions to control the illicit tobacco trade.

Tobacco product portfolio and product design Measures to reduce the addictiveness, palatability and appeal of tobacco products, including:

- Bans on design features and innovations that increase product appeal and palatability, for example, filters and filter ventilation, 'slim' and capsule cigarettes, characterising flavours such as menthol and sweeteners.

Mandated reductions of nicotine to zero or non-addictive levels.
Actions to reduce and then eliminate the production and sale of conventional tobacco products, including:

- Close production facilities and distribution and sales networks.

- Cease online sales.

- Cease supplying the illicit market and take steps to prevent 'leakage' from supply chains to the illicit market (currently large volumes of illicit tobacco include products from PMI and other major tobacco companies). ${ }^{149}$

Actions to support and prevent undermining of these measures, including:

- No development of product design innovations.

- No launches of new conventional tobacco products or brands/brand variants.

- No investment in R\&D and product development, other than to support elimination.

- Progressive elimination of tobacco products with design features designed to increase appeal and palatability.
Other policy measures
Other measures to support reducing smoking prevalence, including:

- Large pictorial warning labels.

- Enhanced cessation support services.

- Smoke-free mass media and social media interventions

- Extensions to smoke-free policies such as smoke-free outdoor dining and bar areas, cars and playgrounds. 
consumption and prevalence. However, implementation is inadequate in most countries. ${ }^{34} 3940$

Adoption of more innovative 'endgame' polices could profoundly accelerate declines in smoking prevalence. ${ }^{41-43}$ These measures include mandated reductions in nicotine content, ${ }^{44} 45$ progressive increases in the legal age of purchase ${ }^{46}$ and substantially reducing the availability of tobacco products. ${ }^{478}$ However, despite some policy proposals, ${ }^{47450}$ only small subnational jurisdictions have so far adopted any of these measures. ${ }^{51}$

A truly transforming company would welcome and never obstruct implementation of policies that support their stated goal to eliminate sales of conventional products in any jurisdiction. This would be particularly true where potential health gains are greatest, such as in countries where a transforming company has the greatest market share, or in LMICs where tobacco product sales are often growing and tobacco control policies are weak. ${ }^{34} 52$ Policy measures should appeal to transforming companies as policies impact all companies equally and would not commercially disadvantage transforming relative to non-transforming companies. A transforming company would also fully respect FCTC Article 5.3, which requires governments to protect policy-making processes from industry influence. ${ }^{53}$ It would reject underhand tactics such as using front groups and third parties to lobby policy makers, and it would disclose all encounters with government agencies and politicians. ${ }^{54} 55$ A visionary and sagacious company might also support legal changes, including amendments to corporate law removing limited liability or fiduciary responsibilities such as profit maximisation, to prioritise social, environmental and health goals. ${ }^{56}$

\section{Evidence for transformation?}

Tobacco companies' behaviour contrasts sharply with genuine transformation. ${ }^{343955}$ For example, PMI's 2014 10-year Corporate Affairs Objectives and Strategies document describes numerous policies it opposes, including many listed in table $1 .{ }^{5758}$ Nor is this opposition merely historical. Companies continue to impede and oppose evidence-based tobacco control policies in multiple countries (see online supplemental table). ${ }^{59-76}$ PMI's recent actions suggest it has maintained the stance outlined in 2014 well beyond announcing its smoke-free vision in $2016 .{ }^{6} 60$

The New Zealand government recently released a draft action plan for its Smokefree 2025 goal that proposes a comprehensive range of tobacco control policy interventions. ${ }^{77}$ Leading tobacco control researchers welcomed the plan as a potential exemplar for ending the smoking epidemic. ${ }^{78}$ Logically, transforming tobacco companies would welcome these innovative ideas and pledge support. Yet, submissions from Imperial Tobacco, British American Tobacco (BAT) and Japan Tobacco International to the consultation opposed all the major policy proposals, including world-leading endgame polices such as denicotinisation of cigarettes and greatly reducing retailer numbers. BAT was caught out encouraging retailers to oppose the plan, ${ }^{79} 80$ and PMI missed the opportunity to express support and did not make a submission.

Criterion 3: evidence of action to reduce uptake and eliminate disparities in use of conventional tobacco products

Smoking, and the harms that follow, ${ }^{81} 82$ are increasingly concentrated in marginalised groups, including people with low incomes and socioeconomic status, ${ }^{83-85}$ Indigenous peoples, ${ }^{85} 86$ people living with mental illness ${ }^{85} 87-89$ and LGBTQI+ groups. ${ }^{85}$ These inequities reflect historic targeting by the tobacco industry, ${ }^{90-98}$ which has maintained the smoking epidemic by recruiting new cohorts of addicted users among youth and young people.
Transforming companies would seek to promote equity and reduce smoking among marginalised groups, and would work to minimise smoking uptake among young people to promote intergenerational equity. ${ }^{99}$ They would set robust targets to minimise, and then rapidly eliminate, the use of their products by these groups.

A transforming company would not oppose policies that could reduce smoking among minority or marginalised communities: for example, menthol bans to reduce smoking among AfricanAmericans in the USA. ${ }^{100}$ Nor would they continue to oppose, as they have in the past, measures aiming to reduce smoking uptake such as Tobacco 21 laws, ${ }^{101-103}$ marketing restrictions and bans on product innovations that appeal to young people.

Transforming companies would also help minimise smoking uptake and smoking-related disparities directly through their own actions: for example, by fully complying with existing policies and regulations, withdrawing conventional products that have high brand share among young people and marginalised groups, ceasing to target marketing to marginalised groups and avoiding price strategies that foster disparities. ${ }^{62} 104$

\section{Evidence for transformation?}

Although tobacco companies have supported youth access restrictions, minimum ( $<18$ years) age of sale laws and schoolbased education programmes, ${ }^{57}$ these measures relocate responsibility to other actors, including retailers and young people themselves. The industry has consistently opposed policy measures that would constrain their activities to foster youth uptake. $^{5455575873104105}$ Tobacco companies continue to obstruct policies that aim to reduce smoking uptake and smokingrelated disparities. ${ }^{60636570106-109}$ They also continue to market conventional products to young people $\mathrm{e}^{110-113}$ and marginalised populations, ${ }^{626369909294104111-114}$ and produce products that appeal preferentially to these groups (see online supplemental table). ${ }^{59616668-70115}$

No tobacco company has proactively withdrawn conventional tobacco product brands popular among young people or marginalised communities nor has any company set targets to reduce or eliminate use of its products among these groups.

\section{Criterion 4: replacement of conventional tobacco products with acceptable alternative products or services}

This is a secondary criterion; evidence of transitioning into alternative products or services can only be compatible with transformation if the first three criteria are met. This criterion requires further debate, as definitions of acceptable alternative products or services may vary and will change as products and markets evolve, and evidence accumulates.

The preferred option would be for a transforming company to transition into completely different (non-nicotine) harmless and non-addictive consumer products or services. There is little evidence of tobacco companies taking this route, although PMI's recent acquisition of three pharmaceutical companies could arguably indicate initiation of such a strategy, if only PMI had fully met the first three criteria. ${ }^{116}$ Until it does so, such acquisitions can be used to falsely signal transformation and also create a perverse 'monopoly of harm' in which PMI can maximise its profits by first causing and then treating lung disease.

Instead, companies that claim to be transforming are developing portfolios of new products such as e-cigarettes, heated tobacco products (HTPs) and nicotine pouches. There is an active and evolving debate about the place of new products in tobacco control, and views differ about whether these products 
offer an acceptable alternative to conventional tobacco products. Positions depend on perceptions of their harmfulness, impact on smoking uptake and quitting, and net benefit (or harm) to population health.

Some tobacco control experts may argue that replacing conventional products with another addictive, although less harmful, product is inconsistent with transformation. For example, in New Zealand many Māori (Indigenous peoples) who led the Tupeka Kore (tobacco free) vision saw eliminating addiction as important as eliminating smoking. ${ }^{117}$ This reasoning views new nicotine and tobacco products as transitional, to be eliminated once conventional product use ceases. ${ }^{118}$

Others view companies transitioning to these new products as consistent with transformation provided the new products are substantially less harmful and help greatly reduce conventional product use, and hence improve population health. ${ }^{119}$ Views about appropriate regulatory structures vary; some regard such products as acceptable only if approved as medical (cessation) products regulated via medical agencies. Others believe new products should be made widely available as consumer products with minimal regulation, and support actively encouraging people who smoke to switch.

If replacing conventional with new products is, in principle, deemed compatible with transformation, a transforming company should still give appropriate priority to their stated aim (see box 1) of enhancing population health rather than focus on maximising sales and profits of the new products.

For example, the transforming company's new nicotine and tobacco products should be independently established as substantially reduced risk products. These products should effectively support full cessation of all nicotine products or switching away from conventional products to sole use of the new products. Their design, marketing and distribution should target only existing conventional product users and lead to minimal use (and hence potential addiction and harm) among non-smokers, particularly adolescents and young people. A transforming company would minimise its new products' appeal to minors and non-smokers. It would not obstruct and would comply fully with measures to minimise youth use, such as marketing and availability restrictions, and welcome external monitoring of product use by these groups. The company would respond to evidence of uptake among youth or non-smokers by ceasing to market and withdrawing products of concern.

Furthermore, a transforming company's new product portfolio would comprise those products least likely (based on emissions, biomarkers and epidemiological data) to cause harm. This criterion implies greater reliance on vaping products rather than HTPs, which likely cause greater harm. ${ }^{120} 121$

\section{Evidence for transformation?}

We are not aware of evidence on tobacco industry diversification into non-nicotine-based products or services, other than some investments in the pharmaceutical sector. ${ }^{116}{ }^{122}$ The TTI does not consider this aspect of transformation, but reported that six of the 15 companies analysed had diversified into new nicotine and tobacco products. However, it concluded that harm reduction progress had been 'extremely limited'; smoked tobacco products dominate product portfolios and made up $97 \%$ of sales volumes across 15 participating tobacco companies in 2019. ${ }^{17}$

Transformation requires a product replacement strategy, not a diversification approach. However, tobacco companies appear to be using new products to augment, rather than replace, conventional product revenue streams. For example, BAT analyst briefings present their new products as additional to, not replacements for, conventional products, and analysis of the global (excluding China) retail value of conventional and new products suggests that overall value is increasing even as the retail value of conventional products declines. ${ }^{6}{ }^{123}$ High prevalence of new product use among youth in many jurisdictions, ${ }^{124-127}$ and evidence that tobacco companies market new products to youth ${ }^{128-132}$ and oppose measures to reduce youth access and appeal, ${ }^{133}$ contradict claims by companies that they do not encourage use among young people.

Furthermore, independent investigations, and even the TTI report, reveal that tobacco companies have mostly marketed their new products in HICs, where purchasing power is greater and conventional products are in decline. They have typically not introduced these products in LMICs, where conventional product sales are often growing. ${ }^{6}{ }^{17} 134$

PMI's product portfolio is dominated by HTPs (notably IQOS), and other companies also market these products. This is problematic, given the lack of independent research on HTPs ${ }^{135-137}$ and lack of cessation efficacy data. ${ }^{120} 121138$ The available evidence suggests HTPs are likely to be more harmful than other new products, ${ }^{120} 121139$ and often result in dual use alongside continued smoking. ${ }^{140-144}$ Marketing strategies present HTPs as premium products that offer higher profit margins than cigarettes. ${ }^{6134}$ These attributes are more consistent with profit maximisation than with eliminating use of conventional products.

\section{Can the tobacco industry transform?}

An additional question is whether the tobacco industry could ever voluntarily transform. Our analysis suggests they cannot genuinely transform and survive in the long term by transitioning to new products and marketing these products only to existing smokers (as they claim to do and criterion 4 requires).

This is because this strategy is not a plausible long-term business model. First, where countries prohibit new products to be sold as consumer products, this transformation route is closed. Second, even where new products are allowed as consumer products, the market will be greatly constrained and eventually decline; as only some smokers will become long-term users of new products and, over time, the number of smokers will decrease through quitting or death, and some new product users will quit. Furthermore, this marketplace will be crowded as transforming tobacco companies compete with each other and with independent manufacturers. Hence, even if new products offered greater profit margins than conventional products, transforming companies relying on these products long term are likely to face extinction or be forced to abandon transformation to address investor resistance and legal requirements to maximise shareholder returns. ${ }^{56}$

Diversifying into non-nicotine products and services, either immediately or following an initial transitional stage in which new nicotine products replace conventional tobacco products, may be the only realistic transformation strategy. This approach would require companies to develop a new business model and eventually effectively cease being tobacco companies. No company has yet adopted this strategy.

A concerning but very plausible alternative scenario is that 'transforming' tobacco companies engage in 'pseudo-transformation'. These companies would take minimal action to reduce production and sales of conventional products and, aided by enhanced legitimacy and influence gained through claimed 'transformation', would continue to impede effective tobacco control policy implementation by arguing that harm reduction renders such policies unnecessary. Meanwhile, they could grow markets for new nicotine products (particularly among youth and young adults) and establish 
a substantial population of addicted long-term users. An industry analyst recently predicted a similar scenario, in which conventional product use would remain common in LMICs but decline rapidly in HICs, where the industry would generate a replacement market of new product users. ${ }^{145}$

The activities of some companies suggest they have adopted this strategy. For example, while PMI proclaims its transformation, its actions and the slow decline in its cigarette sales since adopting its smoke-free vision suggest otherwise. PMI's company reports make clear it has no intention of abandoning smoked tobacco products or leaving that market to competitors: 'For as long as significant legitimate demand for combustible tobacco exists, PMI will continue to sell such products responsibly and seek to maintain our leadership position internationally. ${ }^{26} \mathrm{PMI}$ continues to oppose tobacco control policies; it has launched new cigarette brands, and sells cigarettes with appealing design features like filters, flavours and flavour capsules (see online supplemental table). Its new product portfolio is dominated by relatively higher risk HTPs that it typically markets as a premium product in HICs. ${ }^{6} 134$ 140-142 146

\section{DISCUSSION}

We have developed the first independent definition of tobacco industry transformation, and proposed criteria for evaluating its occurrence. We found no evidence of meaningful transformation judged against the three essential criteria and our analysis suggests replacing conventional products by marketing new products solely to existing smokers is not a viable business model. Even companies with growing new product portfolios show minimal progress in reducing sales of conventional products and continue to oppose tobacco control policies. These companies' new product development and marketing is more consistent with profit maximisation than with eliminating conventional product use, and suggest use of a 'pseudotransformation' strategy.

Our bleak prognosis for industry-led transformation raises the question of where responsibility for elimination of conventional tobacco products should fall: on tobacco companies, on governments or on both? We believe the primary responsibility lies with the tobacco industry to cease producing and marketing a highly addictive and deadly product, and to end their sustained opposition to effective policy measures. However, governments must also demonstrate leadership by implementing comprehensive strategies to eliminate conventional products and appropriately regulate new products to maximise their potential to improve population health while minimising harms (such as uptake by non-smokers). Governments should rigorously enforce FCTC Article 5.3 to protect policy making from industry interference. Limited implementation of core FCTC measures, even in many HICs, and glacial progress in enacting bold endgame measures, indicate much more robust government action is needed. This will require greater political will and recognition of the disparities that urgently need addressing.

Our definition and criteria will benefit from wider debate, which we hope this paper will stimulate. For example, some may think that the timescale for conventional product elimination needs to be longer than 5 years. The public health community must lead this debate, and shape the conceptualisation and the language of transformation. The tobacco industry and its affiliated organisations, such as the FSFW, must not be permitted to set the agenda and control the discourse. We encourage additional work to assess the validity and acceptability and further refine our definition and criteria. Future work could also develop specific metrics to enable monitoring and evaluation of tobacco industry transformation.
In conclusion, tobacco companies' transformation rhetoric is highly questionable. Their record of consumer deception, failure to accelerate reductions in sales of conventional products and continued policy obstruction, suggests they are pursuing a pseudotransformation strategy. The reputational benefits of appearing to transform could increase the industry's legitimacy (or as the PMI strategy puts it, 'establish PMI as a trusted and indispensable partner' $)^{58}$ and enable tobacco companies to influence (ie, obstruct) and deflect attention from effective population-based tobacco control measures and slow the global decline in conventional tobacco product sales.

Transformation recalls the 1954 Frank Statement, which tobacco companies used to maintain credibility and delay policy responses to evidence that smoking caused lung cancer. ${ }^{147}$ Major US tobacco companies denied that smoking was injurious to health and pledged to cooperate closely with public health authorities and fund research that would clarify smoking's health effects. Few would regard those promises as fulfilled.

\section{What this paper adds}

$\Rightarrow$ Some tobacco companies claim that they are 'transforming' by adopting public health goals and transitioning to selling new less harmful nicotine and tobacco products rather than conventional smoked and oral tobacco products. This paper critically examines the industry's claims of transformation by defining transformation, exploring the characteristics of transforming tobacco companies and assessing evidence that transformation is occurring and whether it is feasible.

Acknowledgements We acknowledge the helpful comments of Cynthia Callard and Nick Wilson during the original conceptualisation of the paper, and Lindsay Robertson for comments on early drafts of the manuscript. Sarah Dance provided the analysis of Euromonitor global cigarette sales data. We also thank the reviewers of the manuscript (Libby Smith and two anonymous reviewers) and the Tobacco Control editorial team for their helpful and constructive critique of the manuscript during the peer review process. We believe this has resulted in changes that have clarified and strengthened the paper.

Contributors RE, NK and AG conceived the idea for the paper. RE prepared the first and subsequent drafts. JH, NK and AG provided extensive comments and editing on drafts.

Funding AG and NK acknowledge the support of Bloomberg Philanthropies' Stopping Tobacco Organizations and Products funding (https://www.bloomberg. org/).

Disclaimer The funders had no role in the study design, data collection and analysis, decision to publish or preparation of the manuscript.

Competing interests None declared.

Patient consent for publication Not required.

Provenance and peer review Commissioned; externally peer reviewed.

\section{ORCID iDs}

Richard Edwards http://orcid.org/0000-0003-2264-9823

Janet Hoek http://orcid.org/0000-0003-4362-1539

\section{REFERENCES}

1 Reitsma MB, Fullman N, Ng M, et al. Smoking prevalence and attributable disease burden in 195 countries and territories, 1990-2015: a systematic analysis from the global burden of disease study 2015. The Lancet 2017;389:1885-906.

2 Altria. Our 10-year vision: Altria, 2021. Available: https://www.altria.com/en/aboutaltria/our-10-year-vision [Accessed 9 Jun 2021].

3 British American Tobacco. Our purpose and strategy London: British American tobacco, 2021. Available: https://www.bat.com/strategy [Accessed 9 Jun 2021].

4 British American Tobacco. News release: 2021 first half Pre-Close trading update London: British American tobacco, 2021. Available: https://www.bat.com/group/ sites/UK__9D9KCY.nsf/vwPagesWebLive/DOC3RJ7A [Accessed 9 Jun 2021]. 
5 British American Tobacco. Building the enterprise of the future" performance summary 2020. London: British American Tobacco, 2021.

6 Evans-Reeves KA. Addiction at any cost: Philip Morris international uncovered. Bath: STOP, 2020.

7 Imperial Brands. Our strategy London: imperial brands, 2021. Available: https://www. imperialbrandsplc.com/about-us/Our-strategy.html [Accessed 9 Jun 2021].

8 Philip Morris International. Our transformation Geneva: Philip Morris international, 2020. Available: https://www.pmi.com/our-transformation [Accessed 18 Nov 2020].

9 World Health Organization. Joint statement by the WHO Regional Director for the Eastern Mediterranean and the Head of the Secretariat of WHO FCTC to member states of the region. Geneva: World Health Organiszation, 2021. https://www.who. int/fctc/secretariat/head/statements/2020/joint-emro-director/en/

10 Sweanor D. Tobacco control and the tobacco industry - a failure of understanding and imagination. The Counterfactual, 2018. Available: https://www. clivebates. com/tobacco-control-and-the-tobacco-industry-a-failure-of-understanding-andimagination/ [Accessed 9 Jun 2021].

11 Cummings KM, Ballin S, Sweanor D. The past is not the future in tobacco control. Prev Med 2020;140:106183.

12 Abrams DB, Bates CB, Niaura RS. World Health Organization must stop its baseless and Irresponsible attack on tobacco harm reduction (letter to Tedros Adhanom Ghebreyesus, Director-General World Health Organization), 2021. Available: https:// www.clivebates.com/documents/WNTDLetterMay2021.pdf [Accessed 30 Jun 2021]

13 Malone RE. Word wars and tobacco control: saying what needs saying that we don't yet know how to say, or saying it better. Tob Control 2010;19:261-2.

14 O'Connor R, Durkin SJ, Cohen JE, et al. Thoughts on neologisms and pleonasm in scientific discourse and tobacco control. Tob Control 2021:30:359-60.

15 Hastings G. Why corporate power is a public health priority. BMJ 2012;345:e5124.

16 Wood B, Baker P, Sacks G. Conceptualising the commercial determinants of health using a power lens: a review and synthesis of existing frameworks. Int I Health Policy Manag 2021. doi:10.34172/ijhpm.2021.05. [Epub ahead of print: 25 Jan 2021].

17 Foundation for a Smokefree World. Tobacco transformation index: 2020 index ranking report. Geneva: Foundation for a Smokefree World, 2020.

18 Foundation for a Smokefree World. Tobacco transformation index. Geneva: Foundation for a Smokefree World, 2020. Available: https://www.smokefreeworld. org/advancing-industry-transformation/tobacco-transformation-index/ [Accessed 9 Jun 2021]

19 Foundation for a Smokefree World. Tobacco transformation index: Stakeholder consultation report. Geneva: Foundation for a Smokefree World, 2020.

20 Foundation for a Smokefree World. Tobacco transformation index: 2020 index methodology. Geneva: Foundation for a Smokefree World, 2020.

21 Euromonitor Passport. Global retail volume 2021. Available: https://go.euromonitor. com/passport.html [Accessed 14 Jul 2021].

22 Burki TK. Tobacco transformation index under fire. Lancet Oncol 2020;21:1406.

23 Tobacco tactics. Foundation for a Smoke-Free World's Tobacco Transformation Index. Bath: University of Bath, 2020. Available: https://tobaccotactics.org/wiki/fsfw-tti/ [Accessed 18 Nov 2020].

24 World Health Organization. WHO Framework Convention on Tobacco Control. Geneva: World Health Organization, 2003.

25 Gilmore AB. Understanding the vector in order to plan effective tobacco contro policies: an analysis of contemporary tobacco industry materials. Tob Control 2012;21:119-26.

26 Philip Morris International. Delivering a smokefree future. progress towards a world without cigarettes: integrated report 2019. Geneva: Philip Morris International, 2020 .

27 The Sun. Why we can't stop selling cigarettes - Philip Morris Int'l. London: News International, 2020. https://web.archive.org/web/20200730170531/https:/www. sunnewsonline.com/why-we-cant-stop-selling-cigarettes-philip-morris-int//

28 ASH UK. The UK tobacco industry. London: ASH UK, 2017.

29 Dunkley E. Tobacco giant Philip Morris will stop selling cigarettes in Britain within the next ten years. London: The Mail on Sunday, 2021. Available: https://www. dailymail.co.uk/news/article-9822189/Tobacco-giant-Philip-Morris-stop-sellingcigarettes-Britain-ten-years.html [Accessed 11 Oct 2021].

30 Campaign for Tobacco Free Kids. Philip Morris BOLD: marketing images: campaign for tobacco free kids. Available: https://www.tobaccofreekids.org/media/2019/2019_ 04_10_pmbold [Accessed 30 Nov 2020].

31 STOP. Philip Morris International licensing Marlboro production in Uzbekistan is more evidence its "Unsmoke" rhetoric is a lie. New York: STOP, 2019. https:// exposetobacco.org/news/philip-morris-international-licensing-marlboro-productionin-uzbekistan-is-more-evidence-its-unsmoke-rhetoric-is-a-lie/

32 World Health Organization. WHO global report on trends in prevalence of tobacco smoking 2000-2025. Third edition. Geneva: World Health Organization, 2019.

33 Reitsma MB, Kendrick PJ, Ababneh E, et al. Spatial, temporal, and demographic patterns in prevalence of smoking tobacco use and attributable disease burden in 204 countries and territories, 1990-2019: a systematic analysis from the global burden of disease study 2019. The Lancet 2021;397:2337-60.

34 Anderson C, Becher $\mathrm{H}$, Winkler V. Tobacco control progress in low and middle income countries in comparison to high income countries. Int I Environ Res Public Health $2016 ; 13: 1039$
35 Dubray J, Schwartz R, Chaiton M, et al. The effect of MPOWER on smoking prevalence. Tob Control 2015:24:540-2.

36 Gravely S, Giovino GA, Craig L, et al. Implementation of key demand-reduction measures of the who framework convention on tobacco control and change in smoking prevalence in 126 countries: an association study. Lancet Public Health 2017;2:e166-74.

37 Hoffman SJ, Poirier MJP, Rogers Van Katwyk S, et al. Impact of the WHO Framework Convention on Tobacco Control on global cigarette consumption: quasi-experimenta evaluations using interrupted time series analysis and in-sample forecast event modelling. BMJ 2019;365:12287.

38 Husain MJ, Datta BK, Nargis N, et al. Revisiting the association between worldwide implementation of the MPOWER package and smoking prevalence, 2008-2017. Tob Control 2021:30:630-637.

39 Gilmore AB, Fooks G, Drope J, et al. Exposing and addressing tobacco industry conduct in low-income and middle-income countries. Lancet 2015:385:1029-43.

40 World Health Organization. Who report on the global tobacco epidemic, 2019: offer help to quit tobacco use. Geneva: World Health Organization, 2019.

41 Apelberg BJ, Feirman SP, Salazar E, et al. Potential public health effects of reducing nicotine levels in cigarettes in the United States. N Eng/ J Med 2018:378:1725-33.

42 van der Deen FS, Wilson N, Cleghorn CL, et al. Impact of five tobacco endgame strategies on future smoking prevalence, population health and health system costs: two modelling studies to inform the tobacco endgame. Tob Control 2018;27:278-86

43 Wilson N, Hoek J, Nghiem N. Preliminary high-level modelling estimates of impacts of Denicotinisation on smoking prevalence in Aotearoa New Zealand. medRxiv 2021;23.

44 Benowitz NL, Donny EC, Hatsukami DK. Reduced nicotine content cigarettes, ecigarettes and the cigarette end game. Addiction 2017;112:6-7.

45 Donny EC, Walker N, Hatsukami D, et al. Reducing the nicotine content of combusted tobacco products sold in New Zealand. Tob Control 2017;26:e37-42.

46 Berrick AJ. The tobacco-free generation proposal. Tob Control 2013;22:i22-6.

47 Thornley L, Edwards R, Waa A. Achieving Smokefree Aotearoa by 2025 (ASAP). Wellington: University of Otago (ASPIRE 2025), 2017.

48 Smith EA, Malone RE. An argument for phasing out sales of cigarettes. Tob Control 2020;29:703-8

49 US Food and Drug Administration. Tobacco product standard for nicotine level of combusted cigarettes: advance notice of proposed rulemaking. Fed Regist 2018;83:11818-43.

50 de Leon K, Sarita JT. The Philippines: pioneering the tobacco endgame 2020 Available: https://blogs.bmj.com/tc/2020/01/13/the-philippines-pioneering-thetobacco-endgame/ [Accessed 14 May 2020].

51 Arendt M. Beverly hills, Ca is the new norm for tobacco sales, not the outlier. Tobacco Control Blog. Available: https://blogs.bmj.com/tc/2019/06/13/beverlyhills-ca-is-the-new-norm-for-tobacco-sales-not-the-outlier/ [Accessed 27 Oct 2020].

52 World Health Organization. Global progress report on implementation of the WHO Framework Convention on Tobacco Control. Geneva: World Health Organization, 2018.

53 Global Center for Good Governance in Tobacco Control (GGTC). Handbook on implementation of who FCTC article 5.3: policies and practices that protect against tobacco industry interference. Thammasat University, Thailand: global center for good governance in tobacco control. 2nd edn, 2018.

54 Savell E, Gilmore AB, Fooks G. How does the tobacco industry attempt to influence marketing regulations? A systematic review. PLoS One 2014;9:e87389.

55 Smith KE, Savell E, Gilmore AB. What is known about tobacco industry efforts to influence tobacco Tax? A systematic review of empirical studies. Tob Control 2013;22:e1.

56 Callard C, Thompson D, Collishaw N. Transforming the tobacco market: why the supply of cigarettes should be transferred from for-profit corporations to non-profit enterprises with a public health mandate. Tob Control 2005;14:278-83.

57 Philip Morris International. Corporate Affairs approach and issues (presentation) 2014. Available: https://www.documentcloud.org/public/search/projectid:\% 2033738-the-philip-morris-files

58 Philip Morris International. 10 Year Corporate Affairs Objectives and Strategies [Internal document released as part of Reuters International investigation], 2014. Available: https://www.documentcloud.org/public/search/projectid:\%2033738-thephilip-morris-files

59 Branston JR, Hiscock R, Silver K, et al. Cigarette-like cigarillo introduced to bypass taxation, standardised packaging, minimum pack sizes, and menthol ban in the UK. Tob Control 2021:30:708-711.

60 Campaign for Tobacco Free Kids. Tobacco control laws: Godfrey Phillips India limited vs. Union of India: campaign for tobacco free kids. Available: https://www. tobaccocontrollaws.org/litigation/decisions/in-20180831-godfrey-phillips-indialimited [Accessed 18 Nov 2020].

61 Convenience Store. JTI prepares for menthol ban with new blends and formats. Crawley: William Reed Business Media Ltd, 2020. Available: https://www. conveniencestore.co.uk/products/iti-prepares-for-menthol-ban-with-new-blends-andformats/603346.article [Accessed 29 Nov 2020] 
62 Hiscock R, Branston JR, McNeill A, et al. Tobacco industry strategies undermine government Tax policy: evidence from commercial data. Tob Control 2018;27:488-97.

63 Hiscock R, Silver K, Zatoński M, et al. Tobacco industry tactics to circumvent and undermine the menthol cigarette ban in the UK. Tob Control 2020;29:tobaccocontrol-2020-055769.

64 Oliveira da Silva AL, Bialous SA, Albertassi PGD, et al. The taste of smoke: tobacco industry strategies to prevent the prohibition of additives in tobacco products in Brazil. Tob Control 2019;28:e92-101.

65 Campaign for Tobacco Free Kids. Tobacc control laws: litigation by country France. Japan Tobacco International and others V. Ministry of Health (plain packaging laws) Campaign for Tobacco Free Kids. Available: https://www.tobaccocontrollaws.org/ litigation/decisions/fr-20161223-japan-tobacco-international-an [Accessed 23 Nov 2020].

66 Convenience Store. Imperial tobacco adds new Crushball Cigarillo to JPS players range. Crawley: William Reed Business Media Ltd, 2020. Available: https://www. conveniencestore.co.uk/products/imperial-tobacco-adds-new-crushball-cigarillo-tojps-players-range/647309.article [Accessed 29 Nov 2020].

67 Convenience Store. Imperial launches Rizla flavour cards ahead of menthol cigarette ban. Crawley: William Reed Business Media Ltd, 2019. Available: https://www. conveniencestore.co.uk/tobacco/imperial-launches-rizla-flavour-cards-ahead-ofmenthol-cigarette-ban/600491.article [Accessed 29 Nov 2020].

68 Convenience Store. Signature cigar range expands with a menthol capsule variety. Crawley: William Reed Business Media Ltd, 2020. Available: https://www. conveniencestore.co.uk/tobacco/signature-cigar-range-expands-with-a-mentholcapsule-variety/602023.article [Accessed 29 Nov 2020].

69 McGreevy P. Campaign to overturn California's flavored tobacco sales ban accused of misleading voters Los Angeles: LA Times, 2020. Available: https://www.latimes. com/california/story/2020-10-20/campaign-to-remove-california-flavored-tobaccoban-accused-of-misleading [Accessed 6 Jan 2021].

70 Tobacco tactics. Menthol cigarettes: tobacco industry interests and interference. Bath: University of Bath, 2020. Available: https://tobaccotactics.org/wiki/mentholcigarettes-tobacco-industry-interests-and-interference/ [Accessed 18 Nov 2020].

71 Bayly M, Scollo M, Wakefield MA. Evidence of cushioning of tobacco tax increases in large retailers in Australia. Tob Control 2021. doi:10.1136/ tobaccocontrol-2020-056385. [Epub ahead of print: 11 Jun 2021].

72 Ulucanlar S, Fooks GJ, Gilmore AB. The policy dystopia model: an interpretive analysis of tobacco industry political activity. PLoS Med 2016;13:e1002125.

73 Hawkins B, Holden C, Mackinder S. A multi-level, multi-jurisdictional strategy: transnational tobacco companies' attempts to obstruct tobacco packaging restrictions. Glob Public Health 2019;14:570-83.

74 CSP. Lawsuits Filed to Overturn FDA graphic cigarette warnings: CSP daily news, 2020. Available: https://www.cspdailynews.com/tobacco/lawsuits-filed-overturn-fdagraphic-cigarette-warnings [Accessed 8 Sep 2021].

75 S\&P Global Market Intelligence. Philip Morris USA sues FDA over graphic warning labels requirements, 2020. Available: https://www.spglobal.com/ marketintelligence/en/news-insights/latest-news-headlines/philip-morris-usasues-fda-over-graphic-warning-labels-requirements-58495313 [Accessed 8 Sep 2021].

76 Simpson D. Big tobacco wins 2nd delay of graphic new warning labels: Law360, 2020. Available: https://www.law360.com/articles/1333960/big-tobacco-wins-2nddelay-of-graphic-new-warning-labels [Accessed 8 Sep 2021].

77 Ministry of Health. Proposals for a Smokefree Aotearoa 2025 action plan: discussion document. Wellington: Ministry of Health, 2021.

78 Daube M, Maddox R. Impossible until implemented: New Zealand shows the way. Tob Control 2021;30:361-2.

79 Cheng D. Revealed: big tobacco behind dairy owners' postcard protest at Parliament: New Zealand Herald. Available: https://www.nzherald.co.nz/nz/politics/revealed-bigtobacco-behind-dairy-owners-postcard-protest-at-parliament/LH6HUI76LHLKGOHX 26PCTLNMCE/ [Accessed 30 Jun 2021].

80 Johnsen M. Smokefree group says cigarette purchase age would not dent smoking rates: Radio New Zealand. Available: https://www.rnz.co.nz/news/national/440560/ smokefree-group-says-cigarette-purchase-age-would-not-dent-smoking-rates [Accessed 30 Jun 2021].

81 Jha P, Peto R, Zatonski W, et al. Social inequalities in male mortality, and in male mortality from smoking: indirect estimation from national death rates in England and Wales, Poland, and North America. The Lancet 2006;368:367-70.

82 US National Cancer Institute and World Health Organization. The Economics of Tobacco and Tobacco Control. In: US National Cancer Institute tobacco control monograph. Bethseda, MD: US Department of Health and Human Services, National Institutes of Health, National Cancer Institute; and World Health Organization, 2016

83 Hiscock R, Bauld L, Amos A, et al. Socioeconomic status and smoking: a review. Ann N Y Acad Sci 2012;1248:107-23.

84 Sreeramareddy CT, Harper S, Ernstsen L. Educational and wealth inequalities in tobacco use among men and women in 54 low-income and middle-income countries. Tob Control 2018;27:26-34.

85 Drope J, Liber AC, Cahn Z, et al. Who's still smoking? Disparities in adult cigarette smoking prevalence in the United States. CA Cancer J Clin 2018;68:106-15.
86 Cormier M, Schwartzman K, N'Diaye DS, et al. Proximate determinants of tuberculosis in Indigenous peoples worldwide: a systematic review. Lancet Glob Health 2019;7:e68-80

87 Richardson S, McNeill A, Brose LS. Smoking and quitting behaviours by mental health conditions in Great Britain (1993-2014). Addict Behav 2019;90:14-19.

88 Dickerson F, Schroeder J, Katsafanas E, et al. Cigarette smoking by patients with serious mental illness, 1999-2016: an increasing disparity. Psychiatr Serv 2018:69:147-53.

89 Fluharty M, Taylor AE, Grabski M, et al. The association of cigarette smoking with depression and anxiety: a systematic review. Nicotine Tob Res 2017;19:3-13.

90 Waa A, Maddox R, Nez Henderson P. Big tobacco using Trojan horse tactics to exploit Indigenous peoples. Tob Control 2020;29:e132-3.

91 Brown-Johnson CG, England LJ, Glantz SA, et al. Tobacco industry marketing to low socioeconomic status women in the USA. Tob Control 2014;23:e139-46.

92 Quinlan C. How the tobacco industry exploits LGBTQ people: The Establishment, 2016. Available: https://medium.com/the-establishment/how-the-tobacco-industryexploits-lgbtq-people-15c58364f2bc [Accessed 30 Nov 2020].

93 Campaign for Tobacco Free Kids. Tobacco company marketing to African Americans. Washington,D.C.: Campaign for Tobacco Free Kids, 2018.

94 Lempert LK, Glantz SA. Tobacco industry promotional strategies targeting American Indians/Alaska natives and exploiting tribal sovereignty. Nicotine Tob Res 2019;21:940-8

95 Lee JGL, Sun DL, Schleicher NM, et al. Inequalities in tobacco outlet density by race, ethnicity and socioeconomic status, 2012, USA: results from the ASPiRE study. J Epidemio/ Community Health 2017;71:487-92.

96 Stevens $\mathrm{P}$, Carlson LM, Hinman JM. An analysis of tobacco industry marketing to lesbian, gay, bisexual, and transgender (LGBT) populations: strategies for mainstream tobacco control and prevention. Health Promot Pract 2004;5:129S-34.

97 Iglesias-Rios L, Parascandola M. A historical review of R.J. Reynolds' strategies for marketing tobacco to Hispanics in the United States. Am J Public Health 2013;103:e15-27.

98 Apollonio DE, Malone RE. Marketing to the marginalised: tobacco industry targeting of the homeless and mentally ill. Tob Control 2005;14:409-15.

99 Edwards R, Carter K, Peace J, et al. An examination of smoking initiation rates by age: results from a large longitudinal study in New Zealand. Aust N Z J Public Health 2013;37:516-9

100 Delnevo CD, Ganz 0, Goodwin RD. Banning menthol cigarettes: a social justice issue long overdue. Nicotine Tob Res 2020;22:1673-5.

101 Friedman AS. Tobacco-21 laws: insights from the US experience. Nicotine Tob Res $2019 ; 22$.

102 Friedman AS, RJ W. Do local Tobacco-21 laws reduce smoking among 18 to 20 yearolds? Nicotine Tob Res 2019

103 Ahmad S, Billimek J. Limiting youth access to tobacco: comparing the long-term health impacts of increasing cigarette excise taxes and raising the legal smoking age to 21 in the United States. Health Policy 2007;80:378-91.

104 Gilmore AB, Tavakoly B, Taylor G, et al. Understanding tobacco industry pricing strategy and whether it undermines tobacco tax policy: the example of the UK cigarette market. Addiction 2013;108:1317-26.

105 Schwartz R, Chaiton M, Borland T, et al. Tobacco industry tactics in preparing for menthol ban. Tob Control 2018:27:577.

106 Elliot T. Big Tobacco's shadowy new play: Sydney Morning Herald, 2019. Available: https://www.smh.com.au/lifestyle/health-and-wellness/big-tobacco-s-shadowy-newplay-20190514-p51n5t.html [Accessed 18 Nov 2020].

107 Hoek J, Gendall P, Eckert C, et al. Young adult susceptible non-smokers' and smokers' responses to capsule cigarettes. Tob Control 2019;28:498-505.

108 Benowitz NL, Samet JM. The threat of menthol cigarettes to U.S. public health. $N$ Engl J Med 2011;364:2179-81.

109 McGreevy P. Tobacco industry submits signatures on California referendum to block ban on flavored products sales: Los Angeles Times, 2020. Available: https:// www.latimes.com/california/story/2020-11-24/california-flavored-tobacco-banreferendum-signatures [Accessed 8 Sep 2021].

110 Grant A, Weiger C, Spires M. Technical report on flavored cigarettes at the pointof-sale in Latin America: availability and marketing around primary and secondary schools in five countries. Baltimore, MD: Institute for Global Tobacco Control, Johns Hopkins Bloomberg School of Public Health, 2017

111 Maitin-Shepard M, Correll-Carlyle R, Shaikh S. Tobacco industry targets women and girls as next generation of smokers, 2020. Available: https://web.archive.org/web/ 20200708155016/https:/tobaccoatlas.org/2020/04/07/female-targets/ [Accessed 30 Nov 2020]

112 Soneji S, Knutzen KE, Tan ASL, et al. Online tobacco marketing among US adolescent sexual, gender, racial, and ethnic minorities. Addict Behav 2019;95:189-96.

113 Tan ASL, Hanby EP, Sanders-Jackson A, et al. Inequities in tobacco advertising exposure among young adult sexual, racial and ethnic minorities: examining intersectionality of sexual orientation with race and ethnicity. Tob Control 2021:30:84-93.

114 Moran MB, Heley K, Pierce JP, et al. Ethnic and socioeconomic disparities in recalled exposure to and self-reported impact of tobacco marketing and promotions. Health Commun 2019;34:280-9. 
115 Moodie C, Ford A, Mackintosh A, et al. Are all cigarettes just the same? female's perceptions of slim, coloured, aromatized and capsule cigarettes. Health Educ Res 2015;30:1-12.

116 Philip Morris International. PMI progresses on acquisition of three pioneering pharmaceutical companies to accelerate "Beyond Nicotine" vision. Geneva: Philip Morris International, 2021. Available: https://www.pmi.com/media-center/news/ pmi-progresses-on-acquisition-of-three-pioneering-pharmaceutical-companies-toaccelerate-beyond-nicotine-vision [Accessed 24 Sep 2021]

117 New Zealand Parliament. Inquiry into the tobacco industry in Aotearoa and the consequences of tobacco use for Māori. Report of the Māori Affairs select Committee. Wellington: New Zealand Parliament, 2010.

118 Stephenson J. The end game should not be just Smokefree 2025 but also Vapefree. Public Health Expert blog. Wellington: University of Otago, 2021. https://blogs.otago. ac.nz/pubhealthexpert/the-end-game-should-not-be-just-smokefree-2025-but-alsovapefree/

119 Balfour DJK, Benowitz NL, Colby SM, et al. Balancing consideration of the risks and benefits of e-cigarettes. Am J Public Health 2021;111:1661-72.

120 McNeil A, Brose LS, Calder R. Evidence review of ecigarettes and heated tobacco products 2018. A report commissioned by Public Health England. London: Public Health England, 2018.

121 National Academies of Sciences Engineering and Medicine. Public health consequences of e-cigarettes. Washington, DC: The National Academies Press, 2018

122 Tobacco tactics. Tobacco Company Investments in Pharmaceutical \& NRT Products. Bath: University of Bath, 2021. https://tobaccotactics.org/wiki/tobacco-companyinvestments-in-pharmaceutical-nrt-products/

123 British American Tobacco. Analyst briefing. London: British American Tobacco, 2020. https://www.bat.com/group/sites/uk_9d9kcy.nsf/vwPagesWebLive/DO6FKEVZ/\$ FILE/medMDB5MNZA.pdf?openelement

124 Hammond D, Rynard VL, Reid JL. Changes in prevalence of Vaping among Youths in the United States, Canada, and England from 2017 to 2019. JAMA Pediatr 2020;174:797.

125 Lee SJ, Rees VW, Yossefy N, et al. Youth and young adult use of pod-based electronic cigarettes from 2015 to 2019. JAMA Pediatr 2020;174:714.

126 Vallone DM, Cuccia AF, Briggs J, et al. Electronic cigarette and JUUL use among adolescents and young adults. JAMA Pediatr 2020;174:277.

127 Walker N, Parag V, Wong SF, et al. Use of e-cigarettes and smoked tobacco in youth aged 14-15 years in New Zealand: findings from repeated cross-sectional studies (2014-19). Lancet Public Health 2020;5:e204-12.

128 Hoek J, Freeman B. BAT(NZ) draws on cigarette marketing tactics to launch Vype in New Zealand. Tob Control 2019:28:e162-3.

129 Kirkham C. Exclusive: Philip Morris suspends social media campaign after Reuters exposes young influencers': Reuters, 2019. Available: https://www.reuters.com/article/ us-philipmorris-ecigs-instagram-exclusiv-idUSKCN1SH02K [Accessed November 30 2020].

130 Robertson L, Hoek J, Gilmore A. Regulating vaping and new nicotine products: Are tobacco companies' goals aligned with public health objectives? Public Health Expert blog; March 27 2020. Available: https://blogs.otago.ac.nz/pubhealthexpert/ regulating-vaping-and-new-nicotine-products-are-tobacco-companies-goals-alignedwith-public-health-objectives/ [Accessed 11 Oct 2021].

131 Chapman M. New products, old tricks? concerns big tobacco is targeting youngsters London: Bureau of investigative journalism, 2021. Available: https://www.theb ureauinvestigates.com/stories/2021-02-21/new-products-old-tricks-concerns-bigtobacco-is-targeting-youngsters [Accessed 1 Mar 2021].
132 Stead M, Hitchman SC, Angus K. E-Cigarette marketing in the UK: evidence from adult and youth surveys and policy compliance studies. London: Cancer Research UK, 2021.

133 Finnerty R. Hawaii lawmaker spent years obstructing vaping regulation while receiving thousands from Big Tobacco: Hawai'i Public Radio, 2020. Available: https://www.hawaiipublicradio.org/post/hawaii-lawmaker-spentyears-obstructing-vaping-regulation-while-receiving-thousands-big-tobacco\# stream/0 [Accessed 30 Nov 2020].

134 Jackler RK, Ramamurthi D, Axelrod A. Global Marketing of IQOS The Philip Morris Campaign to Popularize "Heat Not Burn" Tobacco. SRITA White paper. Stanford, CA, 2020.

135 Lasseter T, Bansal P, Wilson T. Special Report - Scientists describe problems in Philip Morris e-cigarette experiments: Reuters, 2017. Available: https://www.reuters.com/ article/uk-tobacco-iqos-science-specialreport/special-report-scientists-describeproblems-in-philip-morris-e-cigarette-experiments-idUKKBN1EE1G8 [Accessed 15 Jan 2020].

136 Moazed F, Chun L, Matthay MA, et al. Assessment of industry data on pulmonary and immunosuppressive effects of IQOS. Tob Control 2018;27:s20-5.

137 Gilmore $A B$, Braznell S. US regulator adds to confusion around heated tobacco products. BMJ 2020;370:m3528.

138 Hartmann-Boyce J, McRobbie H, Lindson N. Electronic cigarettes for smoking cessation. Cochrane Database Syst Rev 2020;10:CD010216.

139 Fried ND, Gardner JD. Heat-not-burn tobacco products: an emerging threat to cardiovascular health. Am J Physiol Heart Circ Physiol 2020;319:H1234-9.

$140 \mathrm{Kim} \mathrm{J}, \mathrm{Yu} \mathrm{H}$, Lee S, et al. Awareness, experience and prevalence of heated tobacco product, IQOS, among young Korean adults. Tob Control 2018;27:s74-7.

$141 \mathrm{Kim} \mathrm{SH}$, Cho H-J. Prevalence and correlates of current use of heated tobacco products among a nationally representative sample of Korean adults: results from a cross-sectional study. Tob Induc Dis 2020;18:66

142 Sutanto E, Miller C, Smith DM, et al. Concurrent daily and non-daily use of heated tobacco products with combustible cigarettes: findings from the 2018 ITC Japan survey. Int J Environ Res Public Health 2020;17:2098.

143 Hwang JH, Ryu DH, Park S-W. Heated tobacco products: cigarette complements, not substitutes. Drug Alcohol Depend 2019;204:107576.

144 Stoklosa M, Cahn Z, Liber A, et al. Effect of IQOS introduction on cigarette sales: evidence of decline and replacement. Tob Control 2020;29:tobaccocontrol2019-054998.

145 Gretler C. Smoking headed for extinction in U.S. by 2050, report says: Bloomberg, 2021. https://www.bloomberg.com/news/articles/2021-03-16/smoking-headed-forextinction-in-u-s-by-2050-report-says

146 Sutanto E, Miller C, Smith DM, et al. Prevalence, use behaviors, and preferences among users of heated tobacco products: findings from the 2018 ITC Japan survey. Int J Environ Res Public Health 2019;16:4630.

147 Cummings KM, Morley CP, Hyland A. Failed promises of the cigarette industry and its effect on consumer misperceptions about the health risks of smoking. Tob Control 2002;11 Suppl 1:i110-7.

148 Philip Morris International. Smoke-Free life Geneva: Philip Morris international, 2020. Available: https://www.pmi.com/smoke-free-life [Accessed 19 Nov 2020].

149 Gilmore AB, Gallagher AWA, Rowell A. Tobacco industry's elaborate attempts to control a global track and trace system and fundamentally undermine the illicit trade protocol. Tob Control 2019;28:127-40 